\title{
Chlorophyll-a Vertical Distribution of Yantai Coastal Waters
}

\author{
Ma Wandong, Wang Qiao, Wu Chuanqing, Yin \\ Shoujing \\ Satellite enviroment center, \\ Ministry of Environmental Protection \\ Beijing, China
}

\author{
Xing Qianguo, Shi Ping, Liu Dongyan \\ Yantai institute of coastal zone research, \\ Chinese Academy of Sciences \\ Yantai, China
}

\begin{abstract}
Many researchers have studied the properties of chlorophyll-a vertical distribution in open ocean waters by now, and little is found for coastal waters. In the study, the chlorophyll-a vertical distribution of Yantai coastal waters is analyzed and a polynomial model is used to appraise the trend. Furthermore, the Gaussian model according to open waters is used to testify the practicability for coastal waters. The ratio between chlorophyll-a and turbidity is also discussed in order to predict the distribution trend. Finally, some conclusions could be achieved: A chlorophyll-a maximum in vertical direction could be seen and the maximum appears at about $6 \sim 8$ meter depth in our research areas. The chlorophyll-a vertical distribution is similar to open ocean waters. Secondly, the euphotic layer is about 6 8 meter depth. Thirdly, under the depth of maximum chlorophyll-a concentration, chlorophyll-a concentration has negative correlation to the turbidity concentration in vertical direction. Based on above conclusion, the total chlorophyll-a could be achieved by calculating definite integrate of the simulation functions. This verifies the relationships of the surface and total chlorophyll-a concentration, which is the basis of primary production by the method of remote sensing.
\end{abstract}

Index Terms - chlorophyll-a; vertical distribution; Yantai coastal waters; Gaussian model; ratio of chlorophyll-a vs turbidity

\section{INTRODUCTION}

Phytoplankton in the world ocean is the main contributor to the primary production, especially in the coastal water because of the input of nutrients substance. And photosynthetic carbon fixation by phytoplanktonic algae in the euphotic zone of the ocean remains controversial, but is thought to be comparable in magnitude to that affected by the terrestrial phytosphere ${ }^{[1]}$. With the development of satellite sensors, the concentration of chlorophyllous pigments within upper layer could be anticipated by some methods ${ }^{[2,3]}$. Besides the horizontal distribution of chlorophyllous pigments concentration, the phenomenon of vertical distribution of them is outstanding. The error of traditional marine primary production assessment could arrive to $30 \% \sim 120 \%$ if vertical distribution of chlorophyll is neglected $^{[4,5]}$.

In most ocean areas, the distribution of chlorophyllous pigments is uneven in the vertical directions although different specific species as well as different seasons and different sea areas, have different depth distribution pattern ${ }^{[6]}$. And there is a maximum value of chlorophyll concentration in the vertical direction $^{[7-9]}$. The relationship between the total amounts and surface concentration of chlorophyll is pursued ${ }^{[10]}$, and some models have been built. Even under this circumstance, the assessment of primary production remains some uncertainty considering the pigment attenuation length (penetration depth) and vertical profile of pigments ${ }^{[11]}$. In the research of Morel and Berthon, 1989 (abbreviated as MB 89 in following text in this article), they give a formulation about the relationship of total and surface chlorophyll concentration, as follows:

$$
C h l_{\text {tot }}=A \times C h l_{s}{ }^{B}
$$

Where $C h l_{\text {tot }}$ is the total amount of chlorophyll concentration; ${ }^{C h l_{s}}$ is the surface concentration of chlorophyll; $\mathrm{A}, \mathrm{B}$ is the empirical coefficients varying according to biooptical properties of specific ocean areas. This model has been verified by following research.

Lewis et $\mathrm{al}^{[12]}$ put forward to the Gaussian models of vertical distribution of chlorophyll concentration of Case 1 waters. The formulation is described as follows:

$$
\operatorname{Chl}(z)=C h l_{0}+\frac{h}{\sigma \sqrt{2 \pi}} \exp \left[-\left(\frac{z-z_{\text {max }}}{\sigma \sqrt{2 \pi}}\right)^{2}\right]
$$

Where $h, z_{\max }, \sigma$ is the parameters varied with bio-optical situations in special areas; $\mathrm{z}$ is the depth; $\operatorname{chl}_{0}$ is the surface concentration of chlorophyll; $\mathrm{Chl}(\mathrm{z})$ is the chlorophyll concentration at $\mathrm{z}$ depth.

Ondercin et $\mathrm{al}^{[13]}$ give a semi-analytical model about the vertical distribution according to the Rrs value. Most of parameters needed in this model are hardly achieved, so the application of this model is limited. But it gives a perspective about the research on chlorophyll vertical distribution from remote sensing reflection (Rrs).

In this article, we analyze the chlorophyll vertical distribution of coastal water of Yellow Sea. The aim is to find the characteristics of vertical distribution of chlorophyll concentration in Case 2 waters.

\section{DATA AND METHODS}

All data are obtained during the same cruise on 14th July 2007. The location of sampling sites (Fig.1) is along the Yantai 
coastal zone of Yellow Sea. The parameters of water quality achieved by YSI instrument.

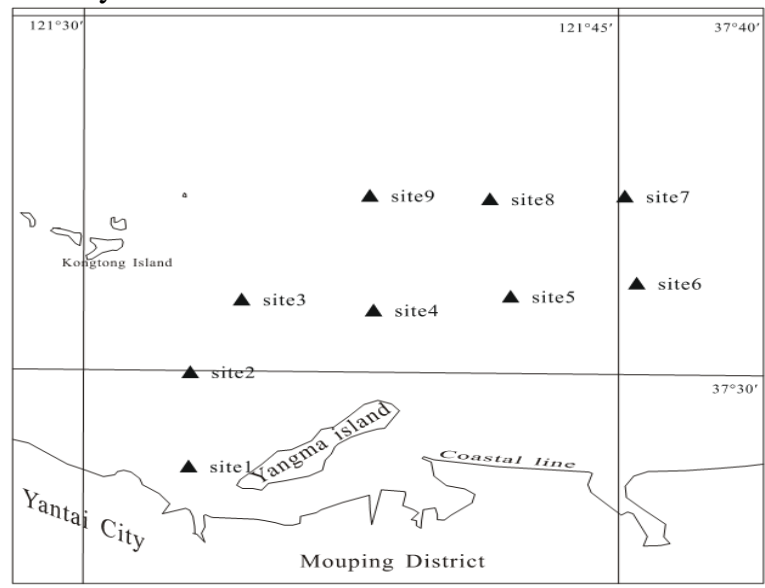

Fig.1 The distribution of sampling sites

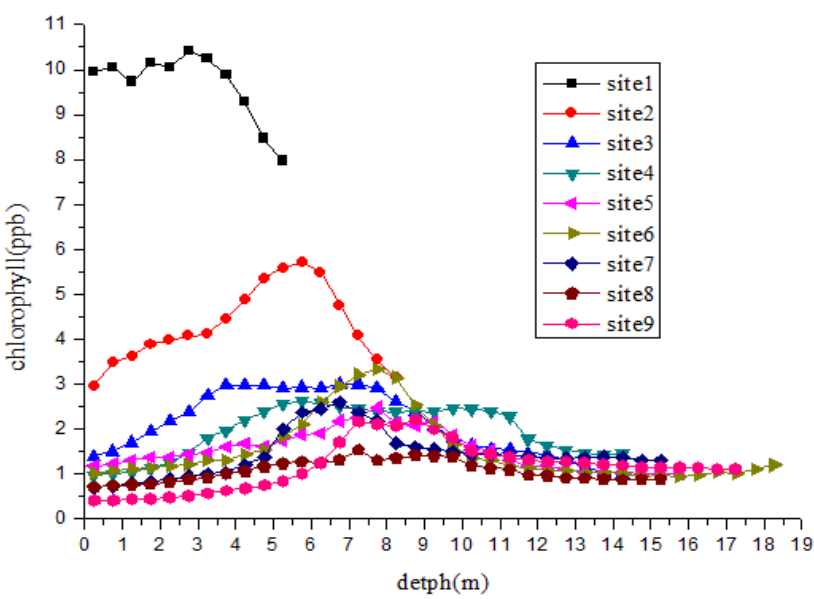

Fig.2 The trend of chlorophyll from different depth

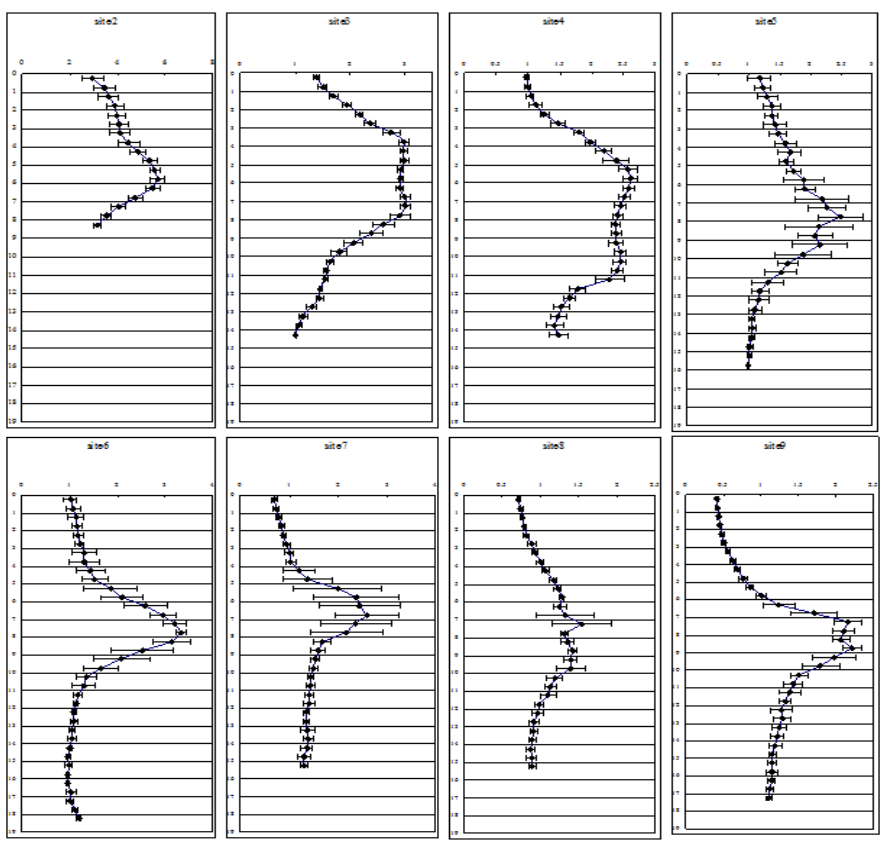

Fig. 3 The vertical distribution of chlorophyll at different depth

\section{1 data processing}

The chlorophyll concentration at different depth is rearranged according to certain interval depth, $50 \mathrm{~cm}$ exception for surface layer: $25 \mathrm{~cm}$. And the data that have been used to describe the vertical profile is an average of $50 \mathrm{~cm}$ to the vertical direction, respectively. The surface concentration is the average of chlorophyll concentration above the depth of $25 \mathrm{~cm}$ below the sea surface.

From Fig. 2, the trends of all sites have similar curves except site 1 . There is a chlorophyll maximum at the depth profile. The data of Site 1 is excluded because of its abnormal chlorophyll concentration and the depth. The same situation happens to site 2 and we regard it as a reference site comparing to other sites. The vertical distribution characters of chlorophyll are described in Fig. 3 .

\subsection{Methodology}

The polynomial model is applied to simulate the trend of chlorophyll vertical distribution. From the Fig. 2, the value of chlorophyll concentration steadily rises to a maximum, and then goes down with varied depth. A simulation of this trend is as follows:

$$
\operatorname{Chl}(z)=\sum_{i=1}^{n}\left(A_{0}+A_{i} Z^{i}\right)
$$

Where $\operatorname{Chl}(z)$ is the chlorophyll concentration at z depth; $A_{0}, A_{i}$

is empirical parameters according for the special area.

We also testify another simulation about chlorophyll concentration in vertical direction: Gaussian formulation. First, the model of Gauss is automatic achieved according to the statistic software. Then we set an initial value to train the model to get better simulated parameters. And the chlorophyllturbidity ratio is also used in this paper to testify the relationship between the chlorophyll and turbidity.

\section{DISCUSSION}

\subsection{The comparison to MB 89}

In the mode of MB 89, the euphotic depth Ze that is defined as that where the downwelling photo-synthetically available radiation $(\mathrm{PAR})$ irradiance is reduced to $1 \%$ of its value at the surface is used to describe the model. In our research, chlorophyll maximum occurs at the bottom of euphotic layer, so as to say that the maximum chlorophyll depth is approximate to the euphotic layer depth, Ze. According to the polynomial formulation, the degree of fitting is higher $\left(\mathrm{R}^{2}>81 \%\right)$ than that of $\mathrm{MB} 89$. The total concentration of chlorophyll is the values of definite integrate from zero to the maximum depth according to the polynomial model. The total concentration is the value of definite integral of formulation 3 .

From Table 1, the total chlorophyll measured by the polynomial model could be comparative to that of results of formulation in MB 89. There is a common trend between the values that simulated by polynomial and that of MB 89 .

3.2 The verification of Gaussian model

According to Lewis et $\mathrm{al}^{[12]}$, the Gaussian model is verified in these cases(in table 2.). There are two parts in the Table 2, one is that the parameters are automatic obtained according to the Gaussian model of statistic software and the other is that 
the initial values of $\mathrm{y} 0$ and $\mathrm{xc}$ are manual restrained according to the observation. The model is represented as follows:

$$
y=y_{0}+\frac{A}{w \sqrt{\pi / 2}} e^{-2 \frac{\left(x-x_{c}\right)^{2}}{w^{2}}}
$$

Where $\mathrm{y}$ is the chlorophyll concentration at $\mathrm{x}$ depth; $\mathrm{y} 0$ is the surface chlorophyll concentration; $\mathrm{x}$ is the depth; $\mathrm{xc}$ is the depth of maximum chlorophyll concentration; $\mathrm{A}$ and $\mathrm{w}$ is the empirical parameters in special sea areas.

TABLE 1 COMPARISON OF TOTAL CHLOROPHYLL TO SIMULATED VALUE IN MB 89

\begin{tabular}{lccccccccccc}
\hline \multirow{2}{*}{ Site } & $\mathrm{R}^{2}$ & \multirow{2}{*}{$\begin{array}{c}\text { Surface } \\
\text { concentration }\end{array}$} & $\begin{array}{c}\text { Total } \\
\text { concentration }\end{array}$ & \multicolumn{6}{c}{ Simulated value according to fomulation in MB 89} \\
\cline { 5 - 10 } & & $2 \mathrm{a}$ & $3 \mathrm{a}$ & $2 \mathrm{~b}$ & $3 \mathrm{~b}$ & $2 \mathrm{c}$ & $3 \mathrm{c}$ & 4 & 5 \\
\hline Site2 & 0.99 & 2.74 & 4.30 & 7.82 & 7.82 & 7.07 & 7.06 & 8.12 & 8.13 & 8.03 & 7.98 \\
Site3 & 0.98 & 1.38 & 2.12 & 3.30 & 3.30 & 3.06 & 3.06 & 3.32 & 3.33 & 3.18 & 3.17 \\
Site4 & 0.97 & 0.98 & 1.95 & 2.82 & 2.82 & 2.64 & 2.64 & 2.79 & 2.80 & 2.64 & 2.63 \\
Site5 & 0.96 & 1.33 & 1.53 & 2.94 & 2.94 & 2.72 & 2.72 & 2.95 & 2.96 & 2.82 & 2.81 \\
Site6 & 0.81 & 1.07 & 1.52 & 2.29 & 2.29 & 2.14 & 2.14 & 2.28 & 2.28 & 2.16 & 2.16 \\
Site 7 & 0.85 & 0.70 & 1.45 & 2.26 & 2.26 & 2.14 & 2.14 & 2.20 & 2.21 & 2.05 & 2.04 \\
Site8 & 0.96 & 0.71 & 1.06 & 2.27 & 2.28 & 2.15 & 2.16 & 2.22 & 2.22 & 2.06 & 2.06 \\
Site9 & 0.92 & 0.41 & 1.18 & 1.56 & 1.56 & 1.51 & 1.51 & 1.48 & 1.49 & 1.35 & 1.35 \\
\hline
\end{tabular}

TABLE 2 THE PARAMETERS ACCORDING TO GAUSS MODEL

\begin{tabular}{|c|c|c|c|c|c|c|c|c|c|c|c|}
\hline \multirow[b]{2}{*}{ site } & \multicolumn{2}{|c|}{$\mathbf{R}^{2}$} & \multicolumn{2}{|c|}{$\mathrm{y}_{0}$} & \multicolumn{2}{|c|}{$\mathbf{x}_{c^{3}}$} & \multicolumn{2}{|c|}{$\mathbf{w}$} & \multicolumn{2}{|c|}{ A } & \multirow[b]{2}{*}{ surface } \\
\hline & I & II & I & II & I & II & I & II & I & II & \\
\hline 2 & 0.90 & 0.37 & 3.45 & 3.21 & 5.33 & 5.75 & 2.58 & 2.98 & 7.25 & 9.27 & 2.74 \\
\hline te 3 & 0.97 & 0.37 & 1.01 & 1.45 & 5.73 & 4.25 & 6.36 & 5.53 & 16.69 & 9.86 & 1.38 \\
\hline te 4 & 0.92 & 0.92 & -0.36 & 0.99 & 7.82 & 5.75 & 11.36 & 7.23 & 41.97 & 13.78 & 9.98 \\
\hline tes & 0.92 & 0.92 & 1.09 & 1.20 & 7.39 & 7.25 & 4.93 & 3.83 & 7.12 & 5.41 & 1.33 \\
\hline te 6 & 0.98 & 0.98 & 1.08 & 1.05 & 7.46 & 7.75 & 2.93 & 2.98 & 8.07 & 8.65 & 1.07 \\
\hline te 7 & 0.80 & 0.98 & 1.16 & 0.72 & 6.73 & 6.25 & 2.47 & 3.40 & 4.39 & 11.16 & 0.70 \\
\hline tes & 0.94 & 0.98 & 0.76 & 0.73 & 7.95 & 9.25 & 5.78 & 6.38 & 4.72 & 5.21 & 0.71 \\
\hline Site9 & 0.73 & 0.37 & 0.81 & 0.42 & 8.77 & 8.25 & 3.91 & 5.53 & 6.37 & 13.12 & 0.41 \\
\hline
\end{tabular}

Note: I denotes the automatic calculated according to the statistic software; II denotes the values that have got through restrained parameters.

From the two series of simulated parameters, residual error of surface chlorophyll concentration of I and II is $0.36,0.03$ respectively. But the residual error of maximum chlorophyll depth is 1.90 and 3.69 , respectively. The automatic simulated value, $\mathrm{y} 0$, and the surface concentration are closer than that of refined model exception for site4. According the simulated results, we could conclude that the automatic Gaussian model is better than the restricted Gaussian model.

From Fig4, the vertical distribution of chlorophyll is qualified with Gaussian model. But if some restrained conditions are added to this model, the fitting degree will change drastically. A great deal of data is needed to predict this trend in future research. And other models should be build to test these factors ${ }^{[13]}$.

3.3 The relationship to the turbidity

Carrick et $\mathrm{al}^{[14]}$ think there is no necessarily correlation
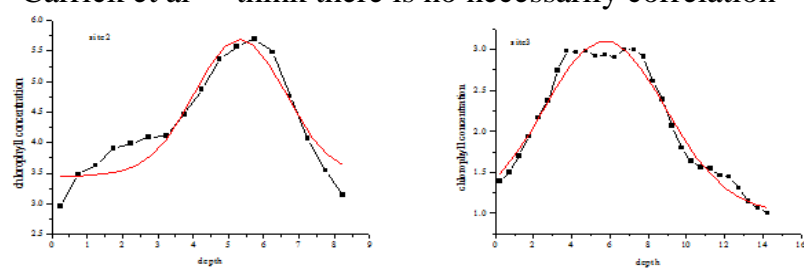
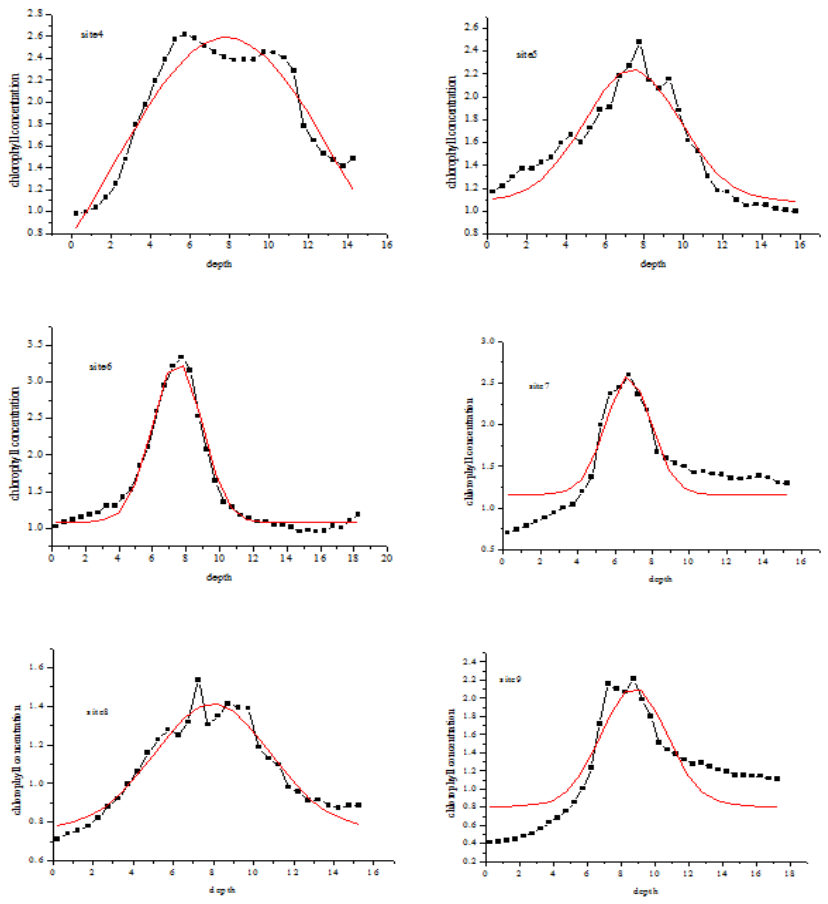

Note: the dotted black lines are the measured data in situ; the red lines are the simulated curve of Gaussian model;

Fig. 4 The simulated Gauss curves of all sites

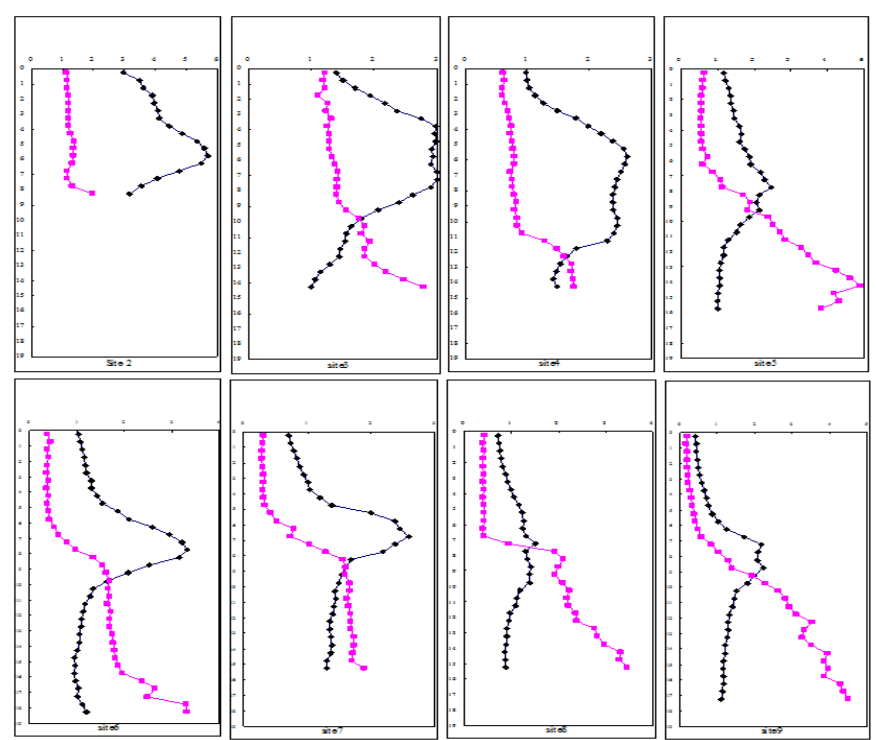

Fig. 5 The relationship between the chlorophyll concentration and turbidity

between chlorophyll concentration and turbidity in shallow, productive aquatic systems. From the parameters that observed, a closer relationship lies between chlorophyll and turbidity (Fig 5). Above the chlorophyll maximum depth, the turbidity is relative steady, but below this depth, there is a negative correlation. The difference between the results is mainly because of different research areas. Although our areas belong to Case 2 waters, there is only a little nutrient input and the impact of land is less than that of the lakes. The waters of our research areas belong to transition type between the common 
Case 2 waters and specific Case 1 waters. In our research areas, the concentration of chlorophyll is constrained to the light because of the increasingly turbidity and the depth ${ }^{[15]}$.

The black curves are chlorophyll concentration and the colored curves are turbidity. The horizontal axis denotes concentration and the vertical axis denotes depth.

According to Irigoien and Castel ${ }^{[15]}$, we get the trend between the chlorophyll-turbidity ratio and depth. From Fig 6, the ratio rapidly goes down from $6 \sim 8$ meter depth.

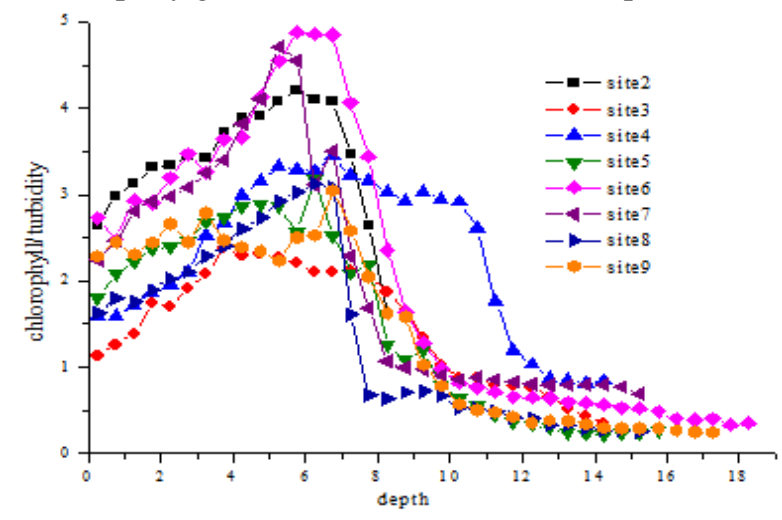

Fig.6 The trend between the chlorophyll-turbidity tario and depth

\section{CONCLUSION}

From the discussion above, we could get: Firstly, the chlorophyll profiles of coastal waters are similar to that of Case 1 waters. The characteristics of vertical distribution of chlorophyll are obvious and there is a maximum value in the chlorophyll vertical profiles. The depth of the maximum chlorophyll concentration is about 6 8 meter deep in our research areas. Secondly, the euphotic layer is about $6 \sim 8$ meter depth. Thirdly, under the depth of maximum chlorophyll concentration, chlorophyll has negative correlation to the turbidity in vertical directions. We also could conclude that the waters of our research areas have the characteristics of both Case 1 and Case 2 waters. This point represents good environment in these water areas. Although the data that have been collected from situ satisfy the models of MB 89 and Gauss, lots of data, such as seasonal and annual data, will be needed to further testify this trend in future research.

\section{ACKNOWLEDGMENT}

The authors acknowledge the cooperate groups of Yantai institute of coastal zone research for providing the field data. This study was supported by Chinese Natural Science Foundation projects (NSFC41271349).

\section{REFERENCES}

[1] Martin J H, Knauer G A, Karl D M, et al.Carbon cycling in the Northeast Pacific[J].Deep Sea Res,1987,34:267-285.

[2] Tyler A N, Svab E, Preston T, et al. Remote sensing of the water quality of shallow lakes:A mixture modelling approach to quantifying phytoplankton in water characterized by high- suspended sediment[J].International Journal of Remote Sensing, 2006, 27(8):1521-1537.

[3] Volpe G, Santoleri R, Vellucci V, et al. The colour of the Mediterranean Sea:Global versus regional bio-optical algorithms evaluation and implication for satellite chlorophyll estimates[J]. Remote Sensing of Environment. 2007,107(4):625-638.

[4] Platt T, Sathyendranath S.Oceanic primary production: estimation by remote sensing at local and regional scales[J]. Science, 1988, 241(4873):1613-1620.

[5] Morel A.Light and marine photosynthesis: A spectral model with geochemical and climatological implications[J]. Progress in Oceanography, 1991,26(3):263-306.

[6] Hajdu S, HÖglander H,Larsson U . Phytoplankton vertical distributions and composition in Baltic Sea cyanobacterial blooms[J]. Harmful Algae, 2007, 6(2):189-205.

[7] Cullen J J.The deep chlorophyll maximum: comparing vertical profiles of chlorophyll a[J]. Can. J. Fish. Aquat. Sci,1982,39:791803.

[8] Pérez V, Fernández E, Maraňón E, et al.Vertical distribution of phytoplankton biomass, production and growth in the Atlantic subtropical gyres[J]. Deep Sea Research Part I: Oceanographic Research Papers, 2006,53(10):1616-1634.

[9] Townsend D W, Bennett S L,Thomas M A. Diel vertical distributions of the red tide dinoflagellate Alexandrium fundyense in the Gulf of Maine[J]. Deep Sea Research Part II: Topical Studies in Oceanography,2005,52(19-21):2593-2602.

[10] Morel A,Berthon J F. Surface pigments, algal biomass profiles, and potential production of the euphotic layer: Relationships reinvestigated in view of remote-sensing applications[J]. Limnology and Oceanography,1989,34(8):1545-1562.

[11] Gordon H R,McCluney W R.Estimation of the depth of sunlight penetration in the sea for remote sensing[J]. Applied Optics, 1975,14(2):413.

[12] Lewis M R, Cullen J J,Platt T. Phytoplankton and thermal structure in the upper ocean: Consequences of nonuniformity in chlorophyll profile[J]. Journal of Geophysical Research, 1983, 88(C4): 2565-2570.

[13] Ondercin D G, Atkinson C A,Kiefer D A. The distribution of bioluminescence and chlorophyll during the late summer in the North Atlantic:Maps and a predictive model[J]. Journal of Geophysical Research, 1995, 100(C4):6575-6590.

[14] Carrick H J, Worth D,Marshall M L.The influence of water circulation on chlorophyll-turbidity relationships in Lake Okeechobee as determined by remote sensing[J]. Journal of Plankton Research, 1994, 16(9):1117-1135.

[15] Irigoien X, Castel J. Light Limitation and Distribution of Chlorophyll Pigments in a Highly Turbid Estuary: the Gironde (SW France)[J].Estuarine, Coastal and Shelf Science, 1997, 44(4):507-517. 